\title{
STUDENTS IN ONLINE DEGREE PROGRAMS: PERCEPTIONS OF COURSE TERM LENGTHS
}

\author{
Sherry Rodrigue, Nicholls State University, sherry.rodrigue@nicholls.edu \\ Ronnie Fanguy, Nicholls State University, ronnie.fanguy@nicholls.edu \\ Lori Soule, Nicholls State University, lorisoule@nicholls.edu \\ BettyKleen, Nicholls State University,betty.kleen@nicholls.edu
}

\begin{abstract}
While online education has been the main topic of many research projects, especially over the past fifteen years, little has been reported concerning term length for online coursework. The authors surveyed students in their university's online degree programs concerning their perceptions of course term lengths. The largely nontraditional-aged respondents perceived that the university's 8-week term lengths for their courses supported faster progress toward program completion, and 90\% favored 8-week term lengths over traditional semester term lengths. Some differences of opinion emerged when questioned about term lengths for courses of various types. When tested for significant differences based on gender, age, classification, and major, few differences were identified. Overall the results that are reported held across age, across classifications, and across majors.
\end{abstract}

Keywords: Online Education, Online Learning, Online Program Student Retention

\section{INTRODUCTION}

A quick review of websites of online degree programs at higher education institutions in the United States reveals that there is no single structure for course length that higher education has embraced. A specific review of the online degree websites of those colleges and universities identified by thebestschools.org (2015) as "The 50 Best Online Colleges" confirms that different schools structure their online degree program terms in different ways.

Like many public universities that have embraced online learning in recent years and expanded their offerings to include fully online degree programs, the authors' university has reached a growth point where administrators and faculty have begun reviewing the practices and procedures in all aspects of its online programs. Currently the online degree programs are managed by the Division of Distance Education, and the course offerings and enrollment of students is handled administratively through the established procedures. In a recent restructuring, a computer information systems faculty member with instructional design experience has been designated as the Director of Online Business Education and provides guidance in the design of online courses within the College of Business. Another full-time CIS faculty member was assigned as advisor to all "Nicholls Online" business majors until recently. Because of growth in the online major, a separate advisor for the business program was hired recently.

Course timelines adhere to the structure established for all programs offered through "Nicholls Online" and are eight weeks in length. One area of concern raised by some faculty at the institution is their frustration with the course work of online degree programs being structured as eight-week courses, while the traditional programs (and any online section offerings in those traditional programs) are typically full-semester (16 week) courses. Those faculty who object to the shorter terms indicate the struggle with facilitating learning in varying course structures operating under different timelines as well as the legitimacy of the shorter time frame in facilitating learning in a quality course. Although the University employs some adjunct faculty in teaching in the fully online programs, many course sections are taught by full-time faculty, typically as overloads. Some faculty present the argument that course offerings should be seamless between the traditional and fully online programs. In addition to the challenge of faculty teaching multiple course timelines during the same semester, administration and support services are 
concerned with this format. Student advising, course enrollment, fees collection and other student support activities that typically take place at the start of each semester are now conducted at the beginning of each eight-week term.

Since the online business program at the authors' university represents approximately one-third of the total online degree program enrollment at the school, the authors have been actively conducting research on best practices, procedures, and structures. As in many fully online degree programs today, the University's enrollment in "Nicholls Online" is predominantly nontraditional students. While the University recognizes that growth in the "Nicholls Online" program is essential to future enrollment growth, retention of students to completion of degree is also an essential component in being able to successfully market various online programs in the future. One logical research step that emerged was to survey those students enrolled in the fully online degree programs to gather their opinions concerning existing course term lengths. While much has been written in the past 15 years concerning online higher education, little information is included on course term length.

\section{LITERATURE REVIEW}

The 2015 Online Report Card - Tracking Online Education in the United States, conducted by the Babson Survey Research Group, is the $13^{\text {th }}$ annual report on online learning status for U.S. higher education (Allen \& Seaman, 2016). The 2015 report notes the number of distance education students was up $3.9 \%$ from the previous study, and almost half of all distance education students in the U.S. take only distance education courses. Public institutions currently enroll more distance education students than private institutions, and over $60 \%$ of chief academic officers report distance learning is very important to their long-term strategies. Interestingly, the report findings also show that in schools boasting the largest online students' enrollments, only about $60 \%$ report faculty acceptance.

Over thirty years ago Bean and Metzner (1985) observed that nontraditional students are difficult to profile, as they come from all geographic locations and socio-economic backgrounds and can range from unemployed to working one or more jobs to retired. Researchers such as Chen (2014) and Ross-Gordon (2011) report that there will be a need for institutions to focus more on nontraditional adult learners as the number of adult learners will increase in the online programs. In a Chronicle of Higher Education blog post, Harvey (2014) reminds institutions that today's students may be aspiring academics but others are better described as career accelerators, working adults who want to obtain a degree to climb a career ladder who value flexible instructional delivery methods.

Numerous researchers over the decades have investigated student retention in online courses. Bean and Metzner's study of nontraditional students' attrition rates found nontraditional students more affected by external environment than by social integration variables that can affect attrition of students of more traditional college age (1985). Over a decade ago, Carr (2000) and Moody (2004) reported adult learners as having higher attrition rates than traditional students. Yet Ross-Gordon (2011) writes that nontraditional students are more likely to exhibit motivation to learn and to prefer self-directed study than traditional students. O'Neil and Fisher (2008) found that online learners, when compared to traditional learners, take more responsibility for their learning and exhibit better self-direction. A key finding from Levy's research shows that the closer a student is to completion in an online program, the greater his/her persistence will be to complete it successfully (2007). In addition to impacting the success of the individual student who drops out of online education, those schools with high attrition rates typically experience problems when promoting their programs and recruiting new students (Willging \& Johnson, 2009).

What factors impact student completion of online programs? Hart's (2012) comprehensive review of the literature related to student persistence in online programs of study noted that various studies identified factors such as student satisfaction with online learning, motivation, peer and family support, time management skills, and increased communication with the instructor as important contributors to students' persistence in completing online educational programs. Levy (2007) likewise found that a key component in student retention was student satisfaction; less satisfied students were more likely to drop out. Herbert's 2007 study of online students also identified several aspects of student satisfaction, such as faculty responsiveness, quality of instruction, and timely 
feedback. Cauble's (2015) study of 197 students in an online nursing graduate program found that GPA was a significant predictor of students' persistence to graduation. In her study she found that neither age, nor gender, nor race/ethnicity were predictors of students' persistence in program completion. While Lee, Choi, and Kim (2013) studied factors between completers and dropout from online learning courses, their research did not look at length of course term.

Rodrigue, Fanguy, Soule, and Kleen (2016) conducted a review of websites of The 50 Best Online Schools as identified by thebestschools.org and found a variety of structures regarding course length for fully online programs at the undergraduate and graduate levels. No single structure was employed by all schools; some employed regular semester-length coursework in their fully online program, while others employed short courses, and yet other institutions employed a mix of regular semester and short-term coursework in their online degrees.

Hoey, McCracken, Gehrett, and Snoeyink (2014), Kuruvilla, Norton, Chalasani, and Gee (2012), and Buckley and Narange (2014) are among the numerous researchers who found that careful design of both administrative structures and academic structures in online programs are needed to ensure both quality programs and good completion rates. These studies, however, do not specifically address term lengths or student opinions concerning term lengths. Although Nash's (2005) research with community college students enrolled in online courses investigated possible methods to improve retention, the study did not ask student opinion on length of term. In one of the few studies that address course length in online programs, Britt's survey research involving both faculty and students in online programs did reveal that online students often fall behind in accelerated course formats (2006).

Because the authors' university is reviewing all aspects of the current online program structure, including term length for courses, it is important to learn more about student opinions regarding timelines of their coursework. However, published literature provides minimal feedback from students concerning this aspect of online education.

\section{PURPOSE OF THE STUDY}

The authors assessed that a logical contribution related to the study of best practices for online education would be a survey of the enrolled students' perceptions regarding course term lengths. Findings could provide important feedback for faculty and administrators as they consider revisions in the online degree policies and procedures. The study did not focus on factors such as faculty responsiveness, quality of instruction, or timely feedback to students, nor were student characteristics prior to admission to the online degree programs researched.

The authors designed a survey to gather answers to the following questions:

- Do online degree students prefer a regular semester term length or shorter term lengths?

- Do online degree students balance employment while pursuing their degree through the online program?

- Do online degree students perceive shorter course terms help them make faster progress toward degree completion?

- Do online degree students have different perceptions of course term lengths most effective for different types of courses (lower-level courses, upper-level courses, math-oriented courses, writing-intensive courses, reading-intensive courses, lecture-based courses, and project-based courses)?

- Are there significantly different responses related to course term lengths based on gender, age, classification, or major?

\section{METHODOLOGY}

The authors designed a survey to be administered to the "Nicholls Online" students through a Google Forms link. The survey focused on collecting data related to the questions detailed above. The University's Human Subjects 
Institutional Review Board reviewed the study plan and survey design and granted approval to proceed with the dissemination of the survey.

\section{DATA ANALYSIS}

Over fall 2015 and spring 2016, 463 different students were enrolled in the online degree programs at the authors' university. Of these 463 students, 95 responded to the survey, although not all participants provided answers to every question in the survey. The characteristics of survey respondents are summarized in figure 1 below. Gender, age, classification, major, work hours, and work situation were used as independent variables for the study.

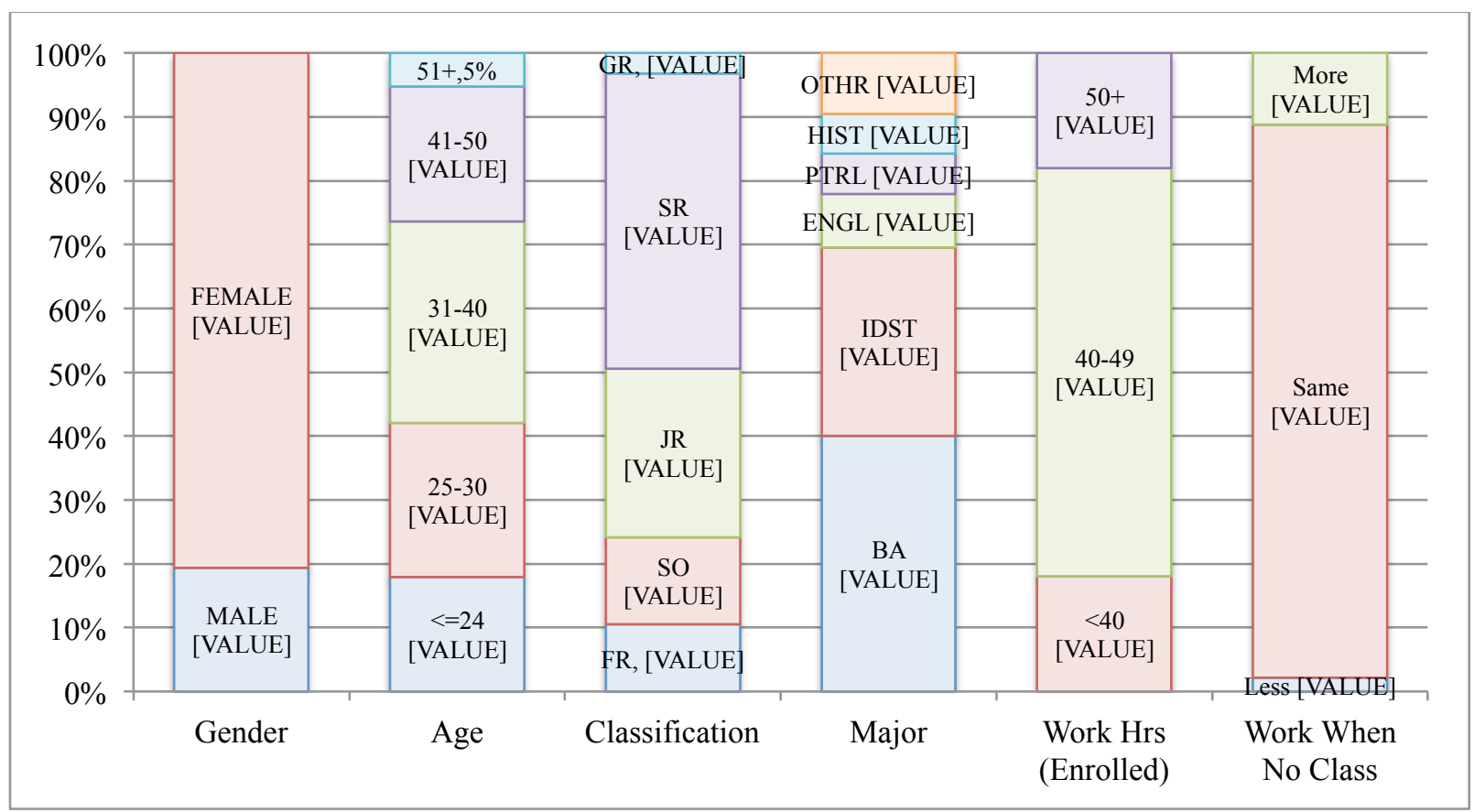

Figure 1. Summary of Responding Online Student Characteristics

In summary, the vast majority of our respondents are female (81\%), non-traditional ( $82 \%$ age 25 and over), upper level students ( $75 \%$ juniors and above), who work full time ( $82 \%$ work 40 hours or more) regardless of whether or not class is in session. Our respondents declared their major across the nine possibilities offered in the online setting. The majority is pursuing either a Bachelor of Science in Business Administration (40\%) or a Bachelor of Interdisciplinary Studies (30\%). Eight percent are pursuing a Bachelor of Arts in English. An Associate of Petroleum Services and a Bachelor of Arts in History are each pursued by $6 \%$ of the respondents. The remaining $9 \%$ of respondents are pursuing Bachelor of Arts in Sociology (4\%), Associate of Science in Safety Technology $(2 \%)$, BSN in Nursing (2\%), and Master of Curriculum and Instruction (1\%).

In our survey instrument, we gauged student opinions about course terms by asking them to respond to 11 items. For the four variables listed below (and depicted in figures 2-4), a 5-point Likert scale was used for the answers. We asked online students to rate how much they liked or disliked each of the following:

- the 8-week course terms that are currently in use for online degree programs

- a mix of 8-week and 16-week classes

- traditional 16-week course terms (with an 8-week summer term)

We also asked respondents to inform us of the degree to which they agree or disagree with the following: 
- Taking 8-week online classes will allow me to finish my degree faster than if the classes followed the traditional semester schedule.

Figures 2 and 3 depict the distribution of student responses to these items, and figure 4 illustrates the mean and standard deviation of these responses. This simple, descriptive statistics review of student responses shows some interesting findings. Figure 2 shows that over $90 \%$ of the respondents like or strongly like the 8 -week terms, whereas only $30 \%$ responded favorably about 16 -week terms. Students feel more favorably (nearly $40 \%$ like or strongly like) in regards to a mix of courses, but the distribution is very similar to the distribution of responses for 16 -week terms. Figure 4 reinforces that students prefer the 8-week courses over 16 -week courses or a mix of 8week and 16-week courses. The mean response of $4.42(S D=0.9)$ for the question related to 8 -week terms is a strong statement of their preference for these courses, especially when compared to the 2.81 mean $(S D=1.2)$ response in regards to 16-week terms.

As shown in figure $3,80 \%$ of respondents agreed or strongly agreed that the existing 8-week course structure helped them progress toward degree completion faster than a traditional 16-week structure. Figure 4 further supports that students perceive that their degree is expedited by 8 -week course terms $(M=4.18, S D=1.2)$.

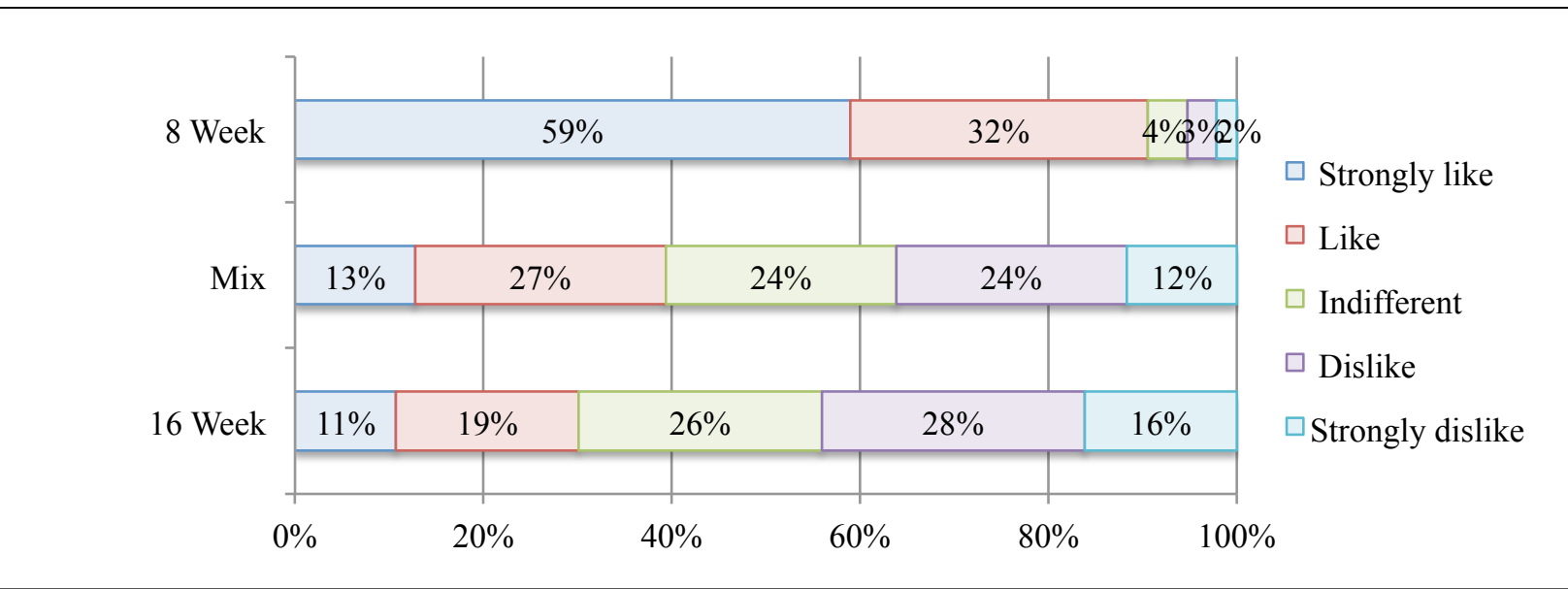

Figure 2. Student Preferences Regarding 8-week Versus 16-week Class Terms

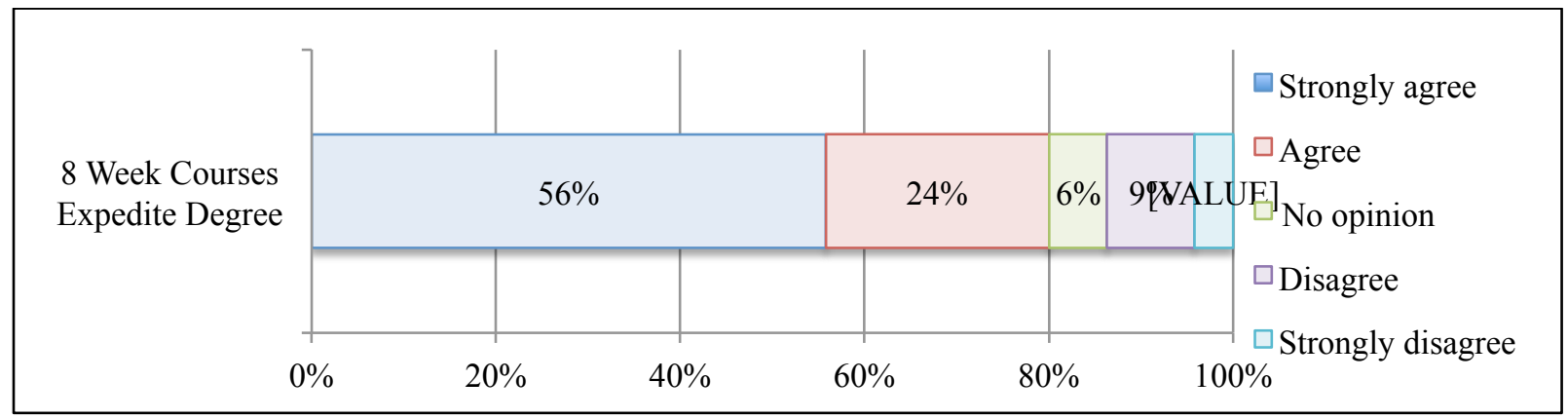

Figure 3. Student Perceptions: Does an 8-Week Course Structure Expedite Degree Completion?

In addition to their overall opinions related to 8-week versus 16 -week terms, our survey instrument also obtained responses from students related to more detailed breakdown of their opinions. We were curious if opinions would change if we asked students about specific types of courses. Using a 3-point scale, we asked students to inform us of their preference for 8-week terms, 16-week terms, or a mix/no preference for the following courses classifications: 
- Basis for course: lecture, project

- Content/teaching method of course: reading, writing, math

- Level of course: upper level (junior, senior, graduate), lower level (freshmen and sophomore)

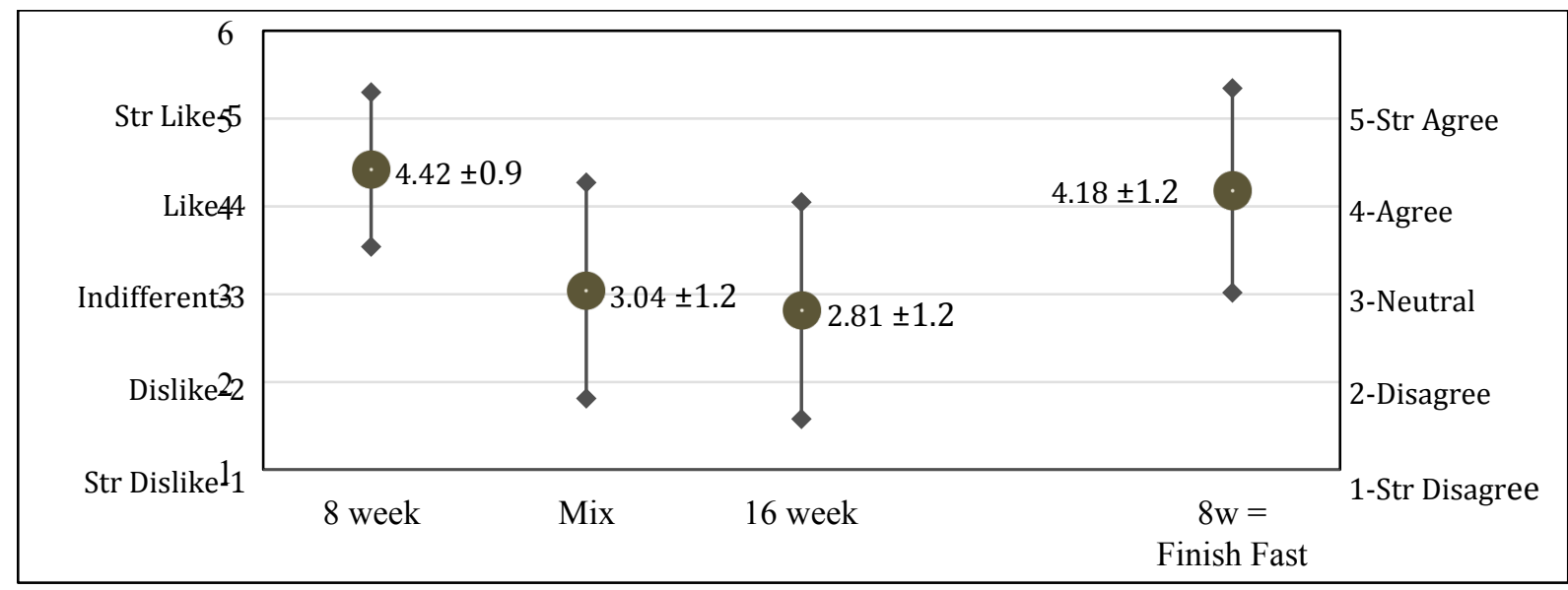

Figure 4. Mean \pm One Standard Deviation of Student Responses Related to Course Terms

When examining responses to these survey items related to term preferences by course type, some differences of opinion do emerge - as depicted in figures 5 and 6 . These figures illustrate that for both lecture-based courses and project-based courses, online degree students prefer an 8-week course structure over a 16-week course structure. This statement is very strong for lecture courses, where only $5 \%$ of students responded that 16 -week terms are preferred and the mean response is lowest of all course types $(M=1.43, S D=0.57)$. When examining courses by content/teaching method (reading, writing, or math), the figure illustrates that students prefer 8-week courses overall. However, for writing-intensive and math-oriented courses, approximately one fourth of the respondents prefer 16-week course terms. We also note that fewer students choose an 8-week term preference for math-intensive courses than for any other course type and that this course type has the highest mean of all course types considered $(M=1.76, S D=0.73)$. In this case, 8 -week terms come in second to a mix of 8 -week and 16 -week terms. This indicates that students are more challenged to complete their work within these courses in the shorter 8-week terms. Apparently, students perceive that having more time to process and apply mathematical concepts is beneficial to them. When examining preferences by the level of the course (lower versus upper level), 8-week terms are the dominant choice. Students are a little more open to 16-week courses for upper-level courses, and only a very small 
percentage of students responded that a strict 16-week schedule is preferable for lower-level courses.

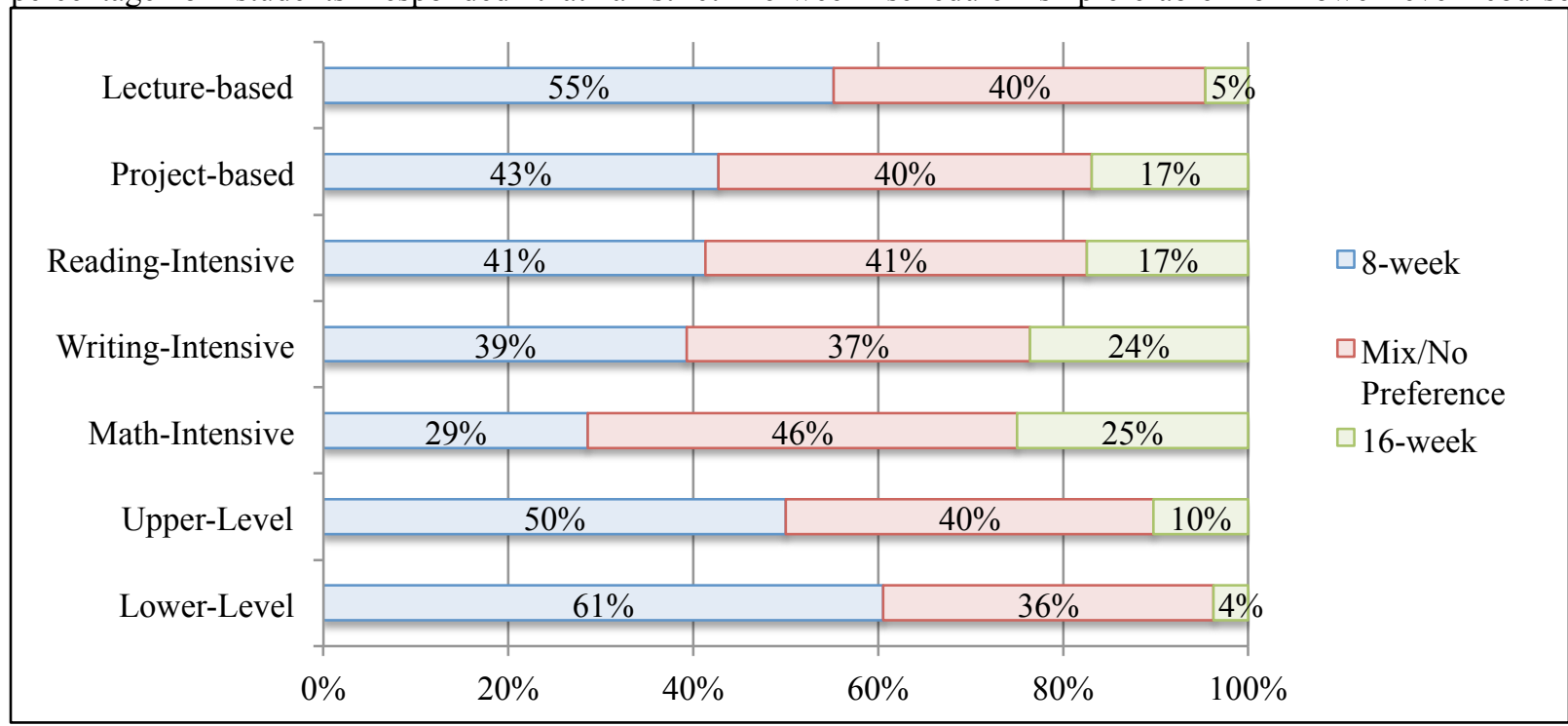

Figure 5. Student Preferences by Course Types

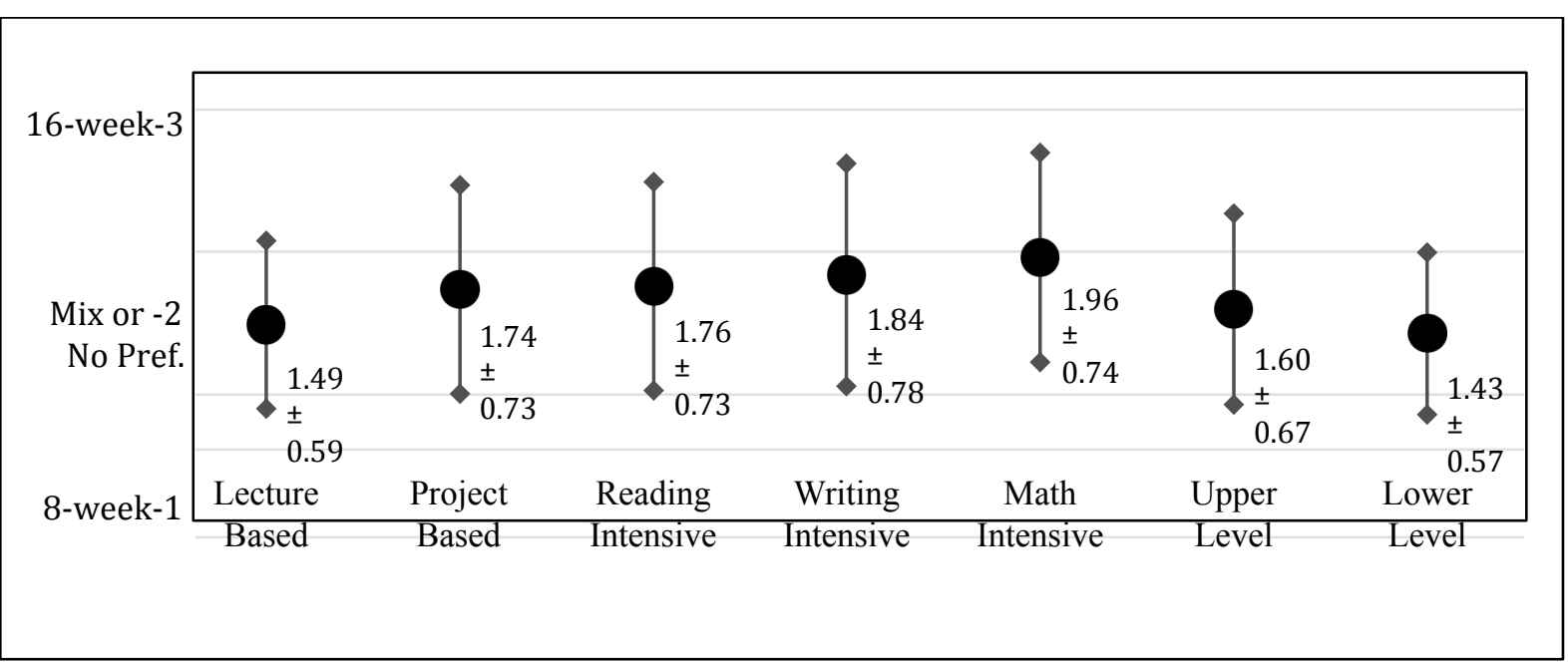

Figure 6. Mean \pm One Standard Deviation of Student Responses Related to Course Types

\section{Independent Samples t-tests}

The authors conducted additional statistical tests on the survey responses collected. Independent samples t-tests were conducted to identify differences in responses by gender. All tests were conducted to the .05 level of significance.

Relating to the 11 questions on the survey, the authors formulated hypotheses (H1-H11) about the differences in the mean of the dependent variables by gender. Of these, only the one hypothesis shown in table 1 yielded statistically significant results $(p=0.05)$. Males $(M=1.22, S D=.428)$ felt even more strongly than females $(M=1.49, S D=$ $.595)$ that shorter course terms for lower-level courses were preferable. 
Table 1: Independent Samples t-test Grouped by Gender

\begin{tabular}{|c|c|c|c|c|}
\hline Hypothesis & $\begin{array}{c}\text { Met Test } \\
\text { Assumption }\end{array}$ & $\begin{array}{c}\text { Test } \\
\text { Outcome }\end{array}$ & $\begin{array}{c}\text { Sig. } \\
\text { Level }\end{array}$ & $\mathbf{N}$ \\
\hline $\begin{array}{l}\text { Item: Lower-level courses offered through } \\
\text { offered as: (8-week, } 16 \text {-week, or a mix of course terms). } \\
H_{0}: \text { Mean Response for Males = Mean Response for Females }\end{array}$ & $\begin{array}{l}\text { Yes, equal variances } \\
\text { not assumed } \\
\text { (sig. }=.001)\end{array}$ & Reject $\mathrm{H}_{\mathrm{o}}$ & .039 & 79 \\
\hline
\end{tabular}

\section{Analysis of Variance}

The authors established a series of 33 ANOVA tests to search for statistically significant differences in responses on the 11 student opinion items (4 Likert-type statements related to overall term preferences/opinions and seven 3-point scale items which drill down to opinions related to specific course types). Each of these 11 items were individually analyzed to search for differences within various groupings based upon 3 different independent variables - age, classification, and major - each considered one at a time. In each case, the respondents were separated into groups based upon the independent variable. Then, the mean scores of the students in each group were compared using a one-way ANOVA. Where relevant, Fisher's LSD post hoc test was used. However, none of these tests resulted in statistically significant differences in the various groupings. The results that are reported held across age, across classifications, and across majors.

\section{CONCLUSIONS AND IMPLICATIONS}

This paper describes a research project aimed at gauging student opinions and perceptions related to course terms for online degree programs. All students enrolled in any of the fully online programs at the authors' university were invited to participate in a survey and share their opinions. Since little in the online education literature addresses the issue of term length for coursework and since no single approach to course term length is used by colleges and universities offering online degree programs, sharing our findings provides a meaningful contribution to those attempting to make policies related to this issue.

In summary, the vast majority of the respondents were non-traditional (age 25 and over) - note that this parallels what the literature suggests concerning online students. In addition, the majority of respondents are female, fulltime workers, majoring in business administration. The opinions and preferences of the respondents are depicted graphically in figures 2 through 6 . Overall, respondents express a strong preference for 8-week courses, the format currently offered for the "Nicholls Online" degrees, and they perceive that this shorter term length helps them progress toward degree completion faster than a traditional 16-week structure. When looking at different types of courses (by teaching method, content, and level), online degree students prefer an 8-week course structure over a 16week course structure. However, for writing-intensive and math-oriented courses this preference is not as strong; approximately one-fourth of the respondents prefer 16-week course terms. Additional statistical tests (independent samples t-tests and analysis of variance) were conducted on our survey responses to determine if there were any differences of opinion in the various groupings of individuals (by gender, age, classification, major). Only one statistically significant difference was found: males feel even more strongly than females that shorter course terms for lower-level courses are preferable. Based on these findings, we conclude that "Nicholls Online" studentsregardless of gender, age, classification, and major-prefer 8-week course terms over 16-week course terms. The summarized results are shown in Figure 7. 


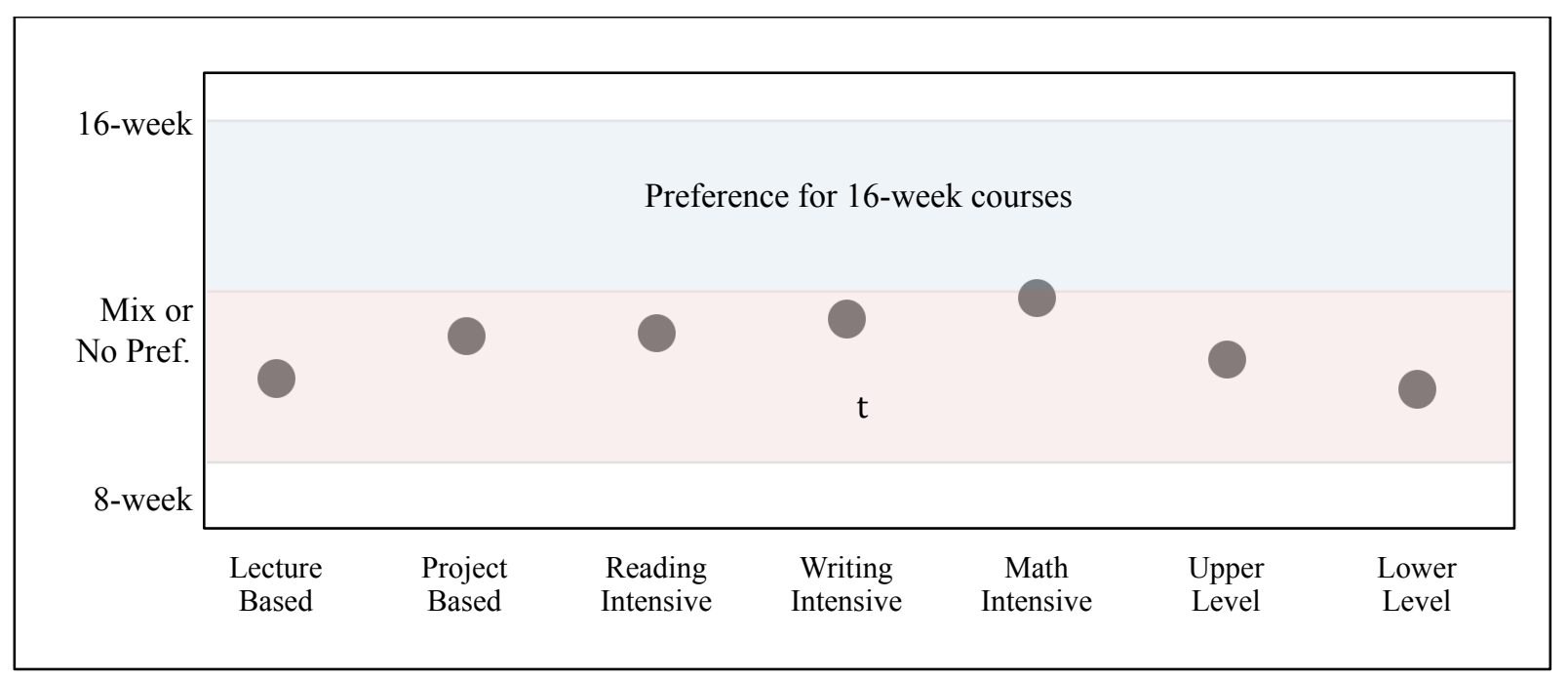

Figure 7. Summary of Course Length Preferences (Average Student Responses)

The message that students are sending is clear: they prefer shorter 8-week courses over the more traditional semester-long (16-week) courses. Being able to focus on two 8-week courses followed by two more taken subsequently is perceived as advantageous over taking four 16-week courses in parallel. While either way yields four course credits within a 16-week period, the preference for 8-week courses is strong. Apparently, it is easier for online students to satisfy degree requirements by taking fewer courses at one time and really concentrating on completing them within the shorter time period. The authors have heard from a number of students who set that shorter 8-week goal in their mind and decide, "I can do this for the next 8 weeks." This is not as easy for them if the course is drawn out over a 16 -week term instead.

If the student decides that 8-week classes are not for them, one alternative is to take more courses during the longer 16-week traditional semester. This requires students to balance material from more classes simultaneously, and it is typically seen as a hindrance to our online students - especially since they are already having to balance their coursework with their work life and home life. This becomes much more difficult if the student is enrolled in classes that have assignment due dates or exams scheduled near the same time. While the course material is covered over a longer period, considerable stress is added as the due dates or test dates approach. Enrolling in more classes simultaneously potentially amplifies this problem. This can be mitigated by careful planning of study time and time for working on assignments and projects. However, many students are not ready for this and are caught off guard once they realize the amount of work that has piled up because of their lack of planning. Students who have experienced this problem may be more likely to resign from the degree program feeling like it is infeasible for them to handle the number of classes required for them to graduate within a reasonable amount of time. Students enrolled in 8-week courses appear to have fewer problems with this issue simply because they are taking fewer classes simultaneously.

While the preferences of the online students support the current 8-week format for "Nicholls Online," it now may be important to further analyze the faculty and administration's viewpoints. Some faculty complain about the complications involved with bringing their traditional 16-week classes into the 8-week format. Furthermore, some administrators complain about the complications of staffing the 8-week classes. University decision makers should proceed with caution when establishing a schedule of classes for online degree programs. With survey respondents clearly favoring 8-week course terms, the shorter course terms are a contributing factor in their retention and continued pursuit of their degrees. We advise that decision makers keep a strong focus on meeting the needs of its online student population, despite what some faculty and administrators might prefer. 


\section{REFERENCES}

Allen, E., \& Seaman, J. (2016). 2015 Online Report Card--Tracking Online Education in the United States. Babson Survey Research Group. http://onlinelearningconsortium.org/read/online-report-card-tracking-onlineeducation-united-states-2015/

Bean, J. P., \& Metzner, B. S. (1985). A conceptual model of nontraditional undergraduate student attrition. Review of Educational Research, 55(4), 485-540.

Britt, R. (2006). Online education: A survey of faculty and students. Radiologic Technology, 77(3), 183-190.

Buckley, I., \& Narang, H. (2014). Exploring the requirements and infrastructure to develop online degree program. Proceedings of the International Conference on e-Learning, e-Business, Enterprise Information Systems, and e-Government (EEE): 1-7. Athens: The Steering Committee of the World Congress in Computer Science, Computer Engineering and Applied Computing.

Carr, S. (2000). As distance education comes of age, the challenge is keeping the students. Chronicle of Higher Education, 46(23), A39-A41.

Cauble, D. (2015). Predictors of Persistence in Online Graduate Nursing Students. https://uta-ir.tdl.org/utair/bitstream/handle/10106/25439/CAUBLE-DISSERTATION-2015.pdf?sequence=1

Chen, J. C. (2014). Teaching nontraditional adult students: Adult learning theories in practice. Teaching in Higher Education, 19(4), 406-418. doi:10.1080/13562517.2013.860101

Hart, C. (2012). Factors associated with student persistence in an online program of study: A review of the literature. Journal of Interactive Online Learning, 11(1), 19-42.

Harvey, T. (2014). What the 6 types of prospective college students are looking for. The Chronicle of Higher Education. http://chronicle.co/blogs/headcount/whata-the-6-types-of-students-who-consider-college-arelooking-for/3833

Herbert, M. (2006). Staying the course: A study in online student satisfaction and retention. Online Journal of Distance Learning Administration, 9(4).

Hoey, R., McCracken, F., Gehrett, M., \& Snoeyink, R. (2014). Evaluating the impact of the administrator and administrative structure of online programs at nonprofit private colleges. Online Journal of Distance Learning Administration, 17(3).

Kuruvilla, A., Norton, S., Chalasani, S., \& Gee, M. (2012). Best practices in initiating online programs at public institutions. Business Education Innovation Journal, 4(2).

Lee, Y., Choi, J., \& Kim, T. (2013). Discriminating factors between completers of and dropouts from online learning courses. British Journal of Educational Technology, 44(2), 328-337. doi:10.1111/j.14678535.2012.01306.x

Levy, Y. (2007). Comparing dropouts and persistence in E-learning courses. Computers and Education, 48(2), 185204.

Moody, J. (2004). Distance education: Why are the attrition rates so high? Quarterly Review of Distance Education, 5(3), 205-210. 


\section{Issues in Information Systems}

Volume 17, Issue II, pp. 222-232, 2016

Nash, R. D. (2005). Course completion rates among distance learners: Identifying possible methods to improve retention. Online Journal of Distance Learning Administration, 8(4). Retrieved from http://www.westga.edu/ distance/ojdla/winter84/nash84.htm

O'Neil, C., \& Fisher, C. (2008). Should I take this course online? The Journal of Nursing Education, 47(2), 53-58.

Rodrigue, S., Fanguy, R., Soule, L., \& Kleen, B. (2016). Information available for prospective online students on university websites. Association of Business Information Systems Conference Proceedings, Oklahoma City, Oklahoma, 40-49.

Ross-Gordon, J. (2011). Research on adult learners: Supporting the needs of a student population that is no longer traditional. Peer Review, 13(1), 26-29.

Thebestschools.org. (2015). The 50 best online colleges for 2015-2016. www.thebestschools.org/rankings/bestonline-colleges/

Willging, P. A., \& Johnson, S. D. (2009). Factors that influence students' decision to drop out of online courses. Journal of Asynchronous Learning Networks, 13(3), 115-127. 